\title{
Sobre o sentido do trabalho fora do enclave de mercado
}

\section{About the meaning of work out of market dimension}

\author{
Débora Paschoal Dourado ${ }^{1}$ \\ Luciana Araujo de Holanda ${ }^{2}$ \\ Michelaine Machado Maciel da Silva ${ }^{3}$ \\ Danielle de Araújo Bispo ${ }^{4}$
}

\section{Resumo}

Ao longo do processo civilizatório, o trabalho adquiriu significados diversos para a humanidade, assumindo formas peculiares de organização e materialidade de acordo com o contexto histórico. Na sociedade contemporânea, o trabalho tende a ocupar um lugar central na vida das pessoas. Com base no pressuposto de que os estudos sobre o trabalho fundamentam-se na atual concepção do trabalho moderno associado ao âmbito das empresas, propôs-se, na presente pesquisa, investigar qual(is) o(s) sentido(s) que indivíduos atuantes em organizações fora do enclave do mercado - mais especificamente em organizações de cultura popular - atribuem ao trabalho. Para responder ao problema posto, utilizou-se o método qualitativo, mais propriamente a história oral, mediante entrevista narrativa com a dirigente de uma organização de cultura popular afro-brasileira. Encontraram-se indícios de que há uma possibilidade de trabalho distinta do modelo empresarial e de que categorias como espiritualidade, resistência, cidadania podem explicar seu sentido. 0 trabalho, para a protagonista da história pesquisada, é uma atividade autodeterminada, externa à relação dinheiro-mercadoria, que gera realização pessoal e da comunidade onde mora/trabalha.

Palavras chaves: sentido; significado; trabalho; organizações culturais.

Abstract

Along the civilizational process, the work acquired several meanings for the humanity, assuming peculiar forms of organization and materiality, in agreement with the historical context. Taking the presupposition that studies about work are based in the current conception of modern work associated to the extent of companies, this research proposed to investigate which(es) meaning(s) individuals, in organizations out of the enclave of market, more specifically, in organizations of popular culture, attribute to their work. To answer to this question, the qualitative method was used, namely the oral history, accomplished through narrative interview with the leader of an organization of Afro-Brazilian popular culture. They were found indications that a different possibility from the business work model exists and that categories as spirituality, resistance, citizenship can explain its sense. The work for the protagonist of the researched history is an activity self oriented, out to the relationship money-merchandise, that generates personal accomplishment and accomplishment for the community where she lives/works.

Keywords: sense; meaning; work; cultural organizations.

\footnotetext{
${ }^{1}$ Doutora em Administração pelo Programa de Pós-Graduação em Administração da Universidade Federal de Pernambuco -PROPAD/UFPE. Professora Pesquisados do grupo de pesquisa Observatório da Realidade Organizacional.Endereço: Avenida Boa Viagem, 4424. Ap. 301 - - Boa Viagem Recife/Pernambuco - Brasil - CEP: 51011000. Email: dcpdourado@gmail.com

2 Doutoranda em Administrção pelo Programa de Pós-Graduação em Administração da Universidade Federal de Pernambuco PROPAD/UFPE . Av. Prof. Moraes Rego, 1235 - Cidade Universitária, Recife - Pernanbuco - Brasil - CEP: 50670901.Email: ludeholanda@gmail.com

${ }_{3}^{3}$ Mestranda em Administração pelo Programa de Pós-Graduação em Administração da Universidade Federal de Pernambuco -PROPAD/UFPE. Endereço: R. Luciana Paiva de Souza, 577a - Cruz de Rebouças - Igarassu/ Pernambuco- CEP: 53630160. Email: michelaine.silva@gmail.com

${ }^{4}$ Estudante de Graduação do Curso de Administração da UFPE.Endereço: Rua Inácio Leopoldo, 91 - Iputinga - Recife/Pernambuco Brasil - CEP: 50670-490. Email: danillefederal@gmail.com

Artigo submetido em fevereiro e aceito em maio de 2009.
} 


\section{Preâmbulo}

O trabalho adquiriu significados diversos e assumiu formas de organização e materialidade peculiares no decorrer do processo civilizatório, variando em cada contexto histórico.

Antunes (2003, p. 167) considera o trabalho "como fonte originária, primária, de realização do ser social, protoforma da atividade humana, fundamento ontológico básico da omnilateralidade humana" (grifo do autor), reconhecendo seu papel fundamental na gênese e na constituição social. O trabalho é, para o autor, uma experiência elementar da vida cotidiana em resposta às necessidades sociais.

Historicamente, o mundo antigo tratou o trabalho com demérito, considerando-o um fardo necessário à sobrevivência, indigno aos homens livres. Somente a partir do século XVI, com a institucionalização da ética protestante, e mais intensamente no século XVIII, com a industrialização e os avanços do modo de produção capitalista, é que o desprezo com o qual os ancestrais gregos e medievais tratavam o trabalho foi substituído por sua valorização, não apenas como ação de sobrevivência, mas como fonte de realização.

Vários autores de diversos campos do conhecimento já mostraram como o trabalho ocupa um lugar central na vida das pessoas nas sociedades industriais e pós-industriais. Desde meados dos anos 50, os sentidos do trabalho têm sido estudados por diferentes abordagens teóricas: sociotécnica, psicanálise e psicossomática, existencialismo moderno, perspectivas construcionista e pós-moderna, com diferentes abordagens metodológicas (MORIN; TONELLI; PLIOPAS, 2003).

O grupo Meaning of Work, MOW, (1987) foi precursor na investigação do tema ao pesquisar a definição de trabalho em diversos países e constatar que ele pode ter, para as pessoas, desde uma condição de neutralidade até de centralidade na identidade pessoal e social (MORIN; TONELLI; PLIOPAS, 2003). O modelo proposto pelo grupo considera o significado do trabalho como um construto psicológico multidimensional e dinâmico, formado da interação entre variáveis pessoais e ambientais e influenciado pelas mudanças no indivíduo. As pesquisas realizadas pelo grupo consistiram em classificar padrões de definição do trabalho que perpassam:

a) seu caráter social: para além de benefícios individuais, contribuir para a sociedade;

b) as concepções negativas: atividade desagradável, obrigatória para sustento; e

c) a concepção neutra: uma atividade remunerada que se realiza em um lugar e horário determinados.

Os resultados demonstraram a complexidade da compreensão do trabalho na sociedade atual e refletem as diferentes visões que as pessoas podem ter com a vivência no trabalho (OLIVEIRA, 2004).

Outro estudo pioneiro na área é o de Hackman e Oldhan (1977 apud OLIVEIRA, 2004, p. 19). Os autores apontam como um trabalho que tem sentido aquele que é importante, útil e legítimo para quem o realiza, destacando três características marcantes para que isso ocorra:

a) a variedade de tarefas que possibilitem a utilização de competências diversas, de forma que o trabalhador se identifique com a execução;

b) um trabalho não alienante, onde o trabalhador consiga identificar todo o processo - desde sua concepção até sua finalização - e perceber seu significado do trabalho, de modo que contribua para o ambiente social, a autonomia, a liberdade e a independência para determinar a forma com que realizará suas tarefas, o que aumenta seu sentimento de responsabilidade em relação a elas; e

c) o retorno sobre seu desempenho nas atividades realizadas, permitindo ao indivíduo que faça os ajustes necessários para melhorar sua performance.

Tanto a pesquisa do MOW quanto o estudo de Hackman e Oldham (1977) e a própria abordagem sociotécnica sobre o trabalho fundamentam-se na perspectiva funcional e tradicionalmente voltada para os interesses organizacionais. Assim, buscam no estudo sobre o trabalho um meio de resgate e de tratamento das condições 
historicamente precárias, com vistas a possibilitar meios de melhoria do desempenho.

Nacionalmente, destacam-se os estudos de Bastos, Pinho e Costa (1995); Morin (1997, 2001); Borges (1999, 2001); Morin, Tonelli e Pliopas (2003); D’Acri (2003) e Piccinini et al. (2004), que replicaram o modelo do grupo MOW em organizações formais guiadas pela lógica capitalista (OLIVEIRA, 2004).

Numa pesquisa bibliográfica exploratória e não exaustiva, percebeu-se que a perspectiva que tem guiado os estudos sobre o trabalho na sociedade contemporânea fundamenta-se na atual concepção do trabalho moderno e associa-o à empresa, sua lógica e objetivos.

Nessa perspectiva, o trabalho precisa, então, orientar-se pela racionalidade econômica que o conduza a resultados quantificáveis de produtividade, eficiência e retorno financeiro. Isso pressupõe uma concepção utilitarista do homem, como se:

[..] o trabalhador devesse adentrar o processo produtivo despojado de sua personalidade e de sua singularidade, de seus fins e de seus desejos próprios, como simples força de trabalho, intercambiável e comparável a qualquer outro trabalhador, servindo a fins que lhe são estranhos $e$ indiferentes (GORZ, 2003, p. 29).

A subordinação e o enquadramento do indivíduo, no atual contexto hipermoderno, ocorre no seio de uma ordem global econômica, política, ideológica, psicológica, percebida como fatalidade inevitável e natural. Assim, as contradições da sociedade neocapitalista são mediadas, mantendo a coerência ideológica/prática e a integração dos agentes (PAGÉS et al., 2006).

Neste processo de mediação, a ciência administrativa tem gerado, na busca por soluções de desempenho para as organizações, inúmeros modelos de gestão ontologicamente comprometidos com este padrão de trabalho.

Devido aos interesses que representam o mainstream dos estudos organizacionais, verifica-se, na literatura, uma escassez de estudos que explorem a questão do trabalho em organizações com formato não empresarial, e naquelas sem fins lucrativos. No campo da cultura, não foram encontrados estudos que discutam o trabalho e seu sentido para os indivíduos que nele atuam. Contudo, outros campos de conhecimento têm se concentrado nesta temática, porém com outra orientação epistemológica, de base mais libertária, como é o caso de estudos da sociologia do trabalho, da economia política e da psicologia.

Na perspectiva da psicodinâmica, por exemplo, Dejours (1987) entende que o trabalho precisa fazer sentido para o próprio sujeito, para seus pares e para a sociedade, sendo o sentido do trabalho formado por dois componentes:

a) O conteúdo significativo em relação ao sujeito, que envolve a dificuldade prática da tarefa, a significação da tarefa acabada em relação a uma profissão (noção esta que abrange a ideia de evolução pessoal e aperfeiçoamento) e o status social ligado, implicitamente, ao posto de trabalho, que permite a construção da identidade pessoal e social do trabalhador.

b) O conteúdo significativo em relação ao objeto, o que envolve mensagens simbólicas que a tarefa pode também veicular para alguém, ou contra alguém.

Assim, os gestos que a atividade do trabalho implica, os instrumentos e materiais utilizados, a atmosfera fornecem um conjunto de símbolos, cuja natureza e encadeamento dependem, ao mesmo tempo, da vida interior do sujeito, ou seja, do que ele introduz de sentido simbólico no que o circunda e no que ele faz. No entanto, Dejours (1987) ressalta que essa separação de conteúdos é arbitrária, na medida em que toda atividade contém ambos, pois o investimento no indivíduo só se renova em virtude do investimento no objeto e viceversa. A significação profunda do trabalho, portanto, é própria para cada indivíduo, e criada com base nas formas particulares desenvolvidas por cada sujeito.

Ao compreender que o sentido que as pessoas conferem ao trabalho perpassa, dialeticamente, o contexto 
macrossocial e organizacional em que estão inseridas, a natureza da atividade laborativa, as características da personalidade e o contexto psicológico, questiona-se sobre a forma do trabalho, seu sentido e seu papel na vida dos indivíduos que atuam em atividades substantivas, cuja base de relação não é a lógica empresarial.

Assim, no presente estudo, propõe-se a análise do sentido do trabalho para indivíduos que atuam em organizações fora do enclave do mercado, mais especificamente em organizações de cultura popular, como tentativa de levantar formas alternativas ao sentido capitalista de trabalho.

Baseando-se no conceito de sistema sociomental proposto por Pagès et al. (2006), que reconhece a interpenetração das instâncias econômica, política, ideológica e psicológica e suas relações com as estruturas inconscientes dos trabalhadores, apresenta-se na sessão a seguir um breve resgate histórico, com o objetivo de explicar a gênese dos sentidos atribuídos ao trabalho e construir um quadro teórico pluridimensional para a análise dos dados que propicie uma compreensão mais ampla sobre o fenômeno.

\section{A gênese e o sentido do trabalho para os indivíduos: uma relação sociomental}

A origem da palavra trabalho é controversa. Para alguns autores, remete ao latim tripaliare, que significa martirizar com o tripalium, um instrumento formado por três estacas utilizadas para manter presos bois ou cavalos difíceis de ferrar. No latim vulgar, significa "pena ou servidão do homem à natureza". Já no grego, há diversos nomes para ações que hoje se agrupam sob o significado de trabalho, não havendo uma única palavra para o vocábulo. O Érgon (do verbo ergazestai) expressa o produto de uma virtude imanente de cada ser, uma potencialidade velada. Essa virtualidade abrange o pratein (de práxis), que é uma atividade natural cujo fim não é produzir um objeto exterior socialmente útil, mas que se atém ao êxito de quem a pratica; já o poiein (de poesis) é o labor que constitui o trabalho técnico do artesão que busca a fabricação de um objeto exterior destinado a satisfazer uma necessidade de natureza social (CUNHA, 1987, p. 49-50). A exemplo do grego é comum entre as línguas europeias, antigas e modernas, haver duas palavras de etimologias diferentes para designar o que para nós, hoje, é trabalho, com a conservação e o uso de ambas, repetidamente, como sinônimas da mesma atividade (ARENDT, 1999, p. 90).

Vale salientar que alguns autores fazem a distinção dos termos sentido e significado. No entanto, comumente, nos trabalhos e pesquisas acadêmicos, os conceitos confundem-se (OLIVEIRA, 2004), como é o caso deste estudo, que adota ambos como sinônimos. Assim, o sentido do trabalho é entendido como uma estrutura afetiva que engloba, além do significado individual, coletivo e social do trabalho, a utilidade da tarefa executada para a organização a que se pertence, a autorrealização e a satisfação, o sentimento de desenvolvimento e evolução pessoal e profissional e a liberdade e autonomia para a execução das tarefas.

Para além da acepção semântica, compreender o significado que os indivíduos atribuem ao trabalho requer o mesmo quanto a interações e encadeamentos entre a realidade externa e o universo mental, entre o objetivo e o subjetivo. São as interconexões entre as instâncias econômica, política, ideológica e psicológica que influenciam o fenômeno individual de atribuição de sentido à ação laborativa.

Pagés et al. (2006) explicam que a relação entre o indivíduo, a organização e seu contexto histórico precisa ser analisada dentro daquilo que denominou de espaço sociomental. Para os autores, este sistema sociomental é composto por relações de correspondência entre as estruturas psicológicas e as estruturas sociais. Dentro desse espaço articulam-se, de forma recíproca, as estruturas econômicas, políticas, ideológicas e psicológicas. Há, portanto, uma dupla gênese, social e psicológica, visto que, na definição do sentido do trabalho, estão envolvidas estruturas manifestas, estruturas fechadas e estruturas de reforços múltiplos não diretamente acessíveis à observação. (PAGÈS et al., 2006, p. 40).

A interação das contradições sociais, das contradições psicológicas e das estruturas sócio-mentais constitui o sistema no sentido amplo do termo [...] Todo sistema social repousa sobre tais articulações 
e que pode ser descrito nestes termos. Ele não pode ser reduzido ao jogo de determinismos sociais, mesmo levando em conta suas repercussões psicológicas, também não pode ser reconstruído no interior da psique, como uma resposta às contradições psicológicas inconscientes (PAGÈS et al., 2006, p. 40).

Sendo o trabalho a materialização da relação do indivíduo com a organização moderna, para compreendê-lo é imprescindível a adoção de um modelo analítico baseado na conjunção de variáveis, desde as estruturais (como fatores econômicos, políticos e ideológicos), até aspectos psicológicos gerados na estrutura mental individual.

Portanto, sob o ponto de vista ontológico, esta investigação buscou conciliar não só a visão determinista de que as estruturas definem o sentido que os trabalhadores dão à sua atividade laborativa, mas também suas motivações e percepções pessoais, numa visão voluntarista sobre o mesmo, mediante associação recíproca destas instâncias.

\section{Instância ideológica}

A forma como se vê o trabalho e seu significado para as pessoas são fortemente influenciados pela ideologia que o orienta. De acordo com Pagès et al. (2006), a ideologia dominante decorre de uma bricolagem de heranças culturais, fatos históricos e influências variadas, segundo as quais só podem impor-se enquanto ideologia se integrarem ideologias particulares daqueles que desejam se submeter.

Entre estas influências, sobretudo no contexto ocidental, a religião tem papel predominante. O sentido que os indivíduos dão ao trabalho ganha importância distinta de acordo com a lógica que orienta as principais perspectivas teológicas.

No contexto das escrituras sagradas, o trabalho foi visto como castigo infligido por Deus ao homem por sua desobediência; com a expulsão do paraíso devido ao pecado original, a humanidade foi punida e, a partir de então, obrigada a extrair seu sustento do suor do rosto, atribuindo ao trabalho um sentido obrigatório, árduo, penoso, fatigante, como relata o livro de Gênesis, que é a base para duas das maiores religiões monoteístas mundiais (Judaísmo e Cristianismo).

Sob a dominação da Igreja Católica no período medieval, o trabalho era valorizado apenas na medida em que contribuía para a resignação cristã e a restauração da pureza da mente, afastando as pessoas da preguiça. Era necessário a fim de garantir a sobrevivência e uma espécie de tributo do servo para o senhor; mas não havia um ritmo acelerado e as jornadas eram ditadas pelas condições climáticas (CARMO, 1992).

Com a reavaliação da concepção cristã promovida pela Reforma Protestante, o princípio da obtenção da riqueza e do lucro, até então condenado pelo Catolicismo, foi legitimado, dando um novo sentido ao trabalho ao incorporar a noção de vocação: tornou-se, então, motivo de orgulho e sacrifício. Trabalhar na vocação era uma atividade ascética por excelência, e Deus abençoava o sucesso do trabalho, que era considerado, em si, a própria finalidade da vida, sendo a falta da vontade de trabalhar um sintoma de ausência de graça divina (WEBER, 2002). Tornou-se natural supor que o homem só era digno aos olhos de Deus se desempenhasse tarefas penosas e renunciantes, de modo a considerar o trabalho um puro ato de virtude inspirado por Deus (THOMPSON, 1987).

O trabalho, como um fim absoluto em si mesmo, não é uma atitude natural, advém da ideia bíblica de vocação e só pode ser produzido por um longo e árduo processo de educação e formação religiosa de todo um grupo social. O homem dominado pela geração e aquisição de riqueza como propósito final da vida, sem consumi-la nem dela desfrutar, é fruto de uma formação protestante cujo ethos estabelece uma inclinação pessoal moralmente neutra como regra de conduta de vida (WEBER, 2002). Tal ética foi o poderoso aliado do capitalismo, embora não intencionalmente (p. 55). Assim, a perspectiva teológica teve papel determinante na formação da ideologia capitalista.

A partir do momento em que as religiões tradicionais mostram-se incapazes de traduzir a vida cotidiana da 
sociedade industrial para o plano espiritual, o mundo profano da produção capitalista sacraliza-se como seu sucedâneo, por constituir-se em um quadro coerente adaptado à realidade vivida cotidianamente (PAGÈS et al., 2006, p. 78):

Em uma sociedade onde os homens transformam profundamente as condições naturais e visam o domínio de seu meio ambiente graças ao desenvolvimento do conhecimento que possuem, toda sua energia é direcionada à redução da contingência. O poder sobrenatural se acha transferido para as estruturas que colaboram para essa transformação, e a veneração se volta para os progressos técnicos que o meio lhes oferece. (PAGÈS et al., 2006, p. 78)

Os valores tradicionais da ideologia humanista cristã, tais como respeito ao indivíduo, valorização do esforço e do sacrifício, perseverança, integridade, etc. são usados para obscurecer as condições reais de exploração no trabalho (PAGÈS et al., 2006).

$\mathrm{Na}$ modernidade, novos valores foram acrescidos aos valores tradicionais, tais como mudança, progresso técnico, eficácia e sucesso individual, fomentando a concepção de uma nova cultura que conduz as pessoas ao papel socialmente definido do trabalho para os indivíduos (PAGÈS et al., 2006, p. 79).

Além dessa instância ideológica, há outras dimensões que influenciam a compreensão e o significado do trabalho para os indivíduos, como a econômica, a política e a psicológica.

\section{Instância econômica}

Segundo Oliveira (1991, p. 6), o trabalho está subordinado a determinadas formas sociais historicamente limitadas e correspondentes a espécies de organizações técnicas que caracterizam os modos de produção.

Nos modos de produção primitivos, o trabalho era realizado coletivamente e estava associado à luta pela sobrevivência na produção de subsistência. Seu excedente é propriedade coletiva e as relações de parentesco determinavam toda atividade produtiva individual dentro da comunidade. Contudo, a sedentarizaçäo levou à substituição da atividade econômica de coleta pela agricultura, esta e a criação de animais de corte e de tração tornaram-se as principais atividades econômicas (OLIVEIRA, 1991).

As formações asiáticas, por sua vez, eram caracterizadas pela presença do Estado e pela ruptura das relações comunitárias por meio da criação de uma sociedade de classes. Nessa formação, foram os excedentes regulares que geraram as desigualdades na distribuição e redistribuição da produção, mediadas pelo Estado que concedia o direito à exploração da terra e arrecadava os impostos. O trabalho era dividido em rural e urbano; este último, uma extensão do primeiro. A organização do trabalho rural era cooperativada e usava de técnicas ainda rudimentares: o camponês era encarregado das atividades agrícolas, da caça, pesca, criação de animais e do artesanato, que era doméstico (OLIVEIRA, 1991).

No mundo grego antigo, o trabalho manual foi estigmatizado pela estrutura escravocrata, o que lhe atribuiu um indicativo de inferioridade e motivo de vergonha, predominando entre os homens livres o ideal da contemplação e prática da política.

No sistema feudal, o trabalho era compulsório, com relações de dominação e servidão, uma vez que o produtor direto não era proprietário da terra, mas trabalhava para o senhor devido à dependência social e jurídica (OLIVEIRA, 1991).

Entre a Idade Média e o Renascimento, houve uma inversão de valores com uma crescente supremacia do "fazer" sobre o "saber", em consequência ao desenvolvimento do trabalho livre, do crescimento das cidades e da criação de pequenas fábricas. O período renascentista fez despontar uma admiração pelo trabalho e seu valor; sobretudo, o trabalho artesanal e artístico (notadamente na escultura, pintura, arquitetura e ciência). Essa supremacia dada ao trabalho manual resgatou-o do desprezo em que o mundo antigo o havia lançado. Ainda assim, as sociedades aristocráticas consideravam o trabalho, em sua totalidade, indigno ao homem de 
qualidade, que se dedicava ao pensamento, à direção dos negócios políticos e religiosos, à gestão de bens e, eventualmente, a transações financeiras (CARMO, 1992).

A partir do século XVII, a germinação das primeiras sementes do modo de produção capitalista levou à valorização do trabalho como elemento implementador do crescimento econômico e das riquezas. Com a ascensão da sociedade urbana industrial, o trabalho foi monetarizado e a força de trabalho mercantilizada. Nesse contexto, o trabalho caracteriza-se:

[...] pela indistinção entre utensílios e homem, pela especialização das funções, pela codificação das tarefas, pela retração de domínio, pela sua calculabilidade, pela falta de coerência entre meios e fins e pela determinação da vida por uma ordem externa e maior (DOURADO, 2007, p. 30).

O trabalho concebido como atividade vital, proveniente da necessidade natural e eterna de intercâmbio entre o homem e a natureza, praticado por livre vontade do homem de controlar as relações materiais entre si e a natureza, tornou-se assalariado, heterodeterminado, fetichizado e estranhado, como denunciava a crítica marxista (ANTUNES, 2003).

Apesar de alienado, fragmentado, rotinizado e despersonalizado, a submissão do homem a essas condições decorre de sua falta de alternativa à sobrevivência. Dessa submissão, por sua vez, deriva o solapamento de sua própria condição de humanidade, fortemente influenciada pela ideologia dominante que se operacionaliza com a banalização das injustiças sociais por ela impingidas (DEJOURS, 2006).

O trabalho passou a ocupar uma posição tão central na vida das pessoas nas sociedades moderna e contemporânea, que o não trabalho, no sentido de desemprego e exclusão do trabalhador do processo social de produção de serviços e riquezas, é que assumiu conotação negativa.

Gorz (1982) explica que esta centralidade do trabalho ganha força com a crise do capitalismo, quando ocorre a substituição da classe operária pela "não-classe-de-não-trabalhadores", composta por pessoas expulsas do mercado de trabalho formal, que tem o emprego como atividade provisória, desvinculada do processo produtivo e nenhuma concepção de sociedade futura. Trata-se de uma denúncia sobre a situação de diversas pessoas que foram expulsas do mercado formal, seja pela automação, pela informatização etc., e que ficam pressionadas pela sociedade a encontrar uma identidade no trabalho, sem mesmo tê-lo. Assim, refugiam-se em atividades provisórias e alternativas como paliativo à falta de emprego formal, às quais o autor chama de emprego precário ou subemprego.

Há que se observar, nesta classificação gorziana, que a "não-classe-de-não-trabalhadores" é composta por pessoas sem opção, que adentram no mercado de trabalho informal por não encontrar espaço no mercado de trabalho formal - portanto, a falta de alternativa parece ser o elemento classificador deste mercado. Diante da ausência de alternativas, essa parcela de trabalhadores se volta para atividades temporárias e precarizadas, mantendo um sentido de trabalho moralmente estabelecido. Desta forma e de maneira sagaz, o capital transfere para o trabalhador a responsabilidade de obter seu próprio emprego, em vez de assumir que o desemprego é estrutural, tendo sido gerado pelas transformações políticas, econômicas, tecnológicas e de gestão.

Tais facetas, historicamente impostas pelo sistema de produção, acarretam modificações no modo como o trabalho é compreendido em cada um dos momentos.

\section{Instância política}

As organizações têm desempenhado o papel fundamental de mediar as contradições do sistema econômico vigente, mais propriamente o conflito de interesses do capital e dos trabalhadores.

Destarte, configura-se como um sistema dinâmico de respostas a contradições, e não como um conjunto de dados, objetivos, capital, restrições, mão-de-obra, procedimentos etc., que a teoria das organizações de cunho positivista postula (PAGÈS et al., 2006). 
Com políticas contraditórias, que aliam fortes restrições a grandes vantagens oferecidas, os indivíduos introjetam as contradições que lhes são externas e de origens desconhecidas e consolidam a ideologia oficial, permitindo que a organização evite a eclosão de conflitos. Além desses processos, a mediação envolve também abstração, desterritorialização e individualização, o que leva o indivíduo a se isolar e colaborar ativamente para sua submissão e controle (PAGÈS et al., 2006).

É preciso entender que o trabalho, tal como é exercido hoje, tem papel político-funcional no atual contexto social, ou seja, a maneira como é exercido e controlado decorre de uma relação de poder inerente à relação capital-trabalho e se configura como medida criada pelo próprio sistema para manter seu poder de dominação.

A administração tem encontrado formas de lidar com o conflito essencial entre indivíduo e organização, propondo práticas gerenciais cada vez mais sofisticadas de controle do indivíduo no trabalho, em busca de resultados progressivos de desempenho.

A passagem da gestão por ordens para a gestão via regulamentos é uma característica fundamental das novas formas de poder e impactam a forma como o trabalho é compreendido e realizado (PAGÈS et al., 2006).

Para Organista (2006), o ajuste da aparente redução do tempo concedido ao trabalho no contexto das organizações modernas trata-se de uma tática para continuar com o poder e a exploração, próprios da lógica capitalista. "O capitalismo não tornou indispensáveis as formas de trabalho precário, temporário e informal [...] tornou-os interdependentes e funcionais ao núcleo central do capitalismo" (Ibid, p. 66).

Offe (1989 apud ORGANISTA, 2006) adverte que o capitalismo está se tornando cada vez mais organizado, viabilizado por formas de administração à distância, cuja decorrência é uma pseudoautonomia. Este fenômeno ocorre com a dispersão, a mobilidade geográfica e as respostas flexíveis nos mercados de trabalho, nos processos de trabalho e nos mercados de consumo, tudo isso acompanhado de pesadas doses de inovação tecnológica, de produto e institucional.

Na ótica de Pagès et al. (1993), a organização media seus conflitos estendendo-se a domínios diversos. Quando propõe participação e autonomia, faz uso de instâncias políticas de controle social, por meio de técnicas de administração à distância cujo respeito às diretrizes centrais da empresa proporciona o desenvolvimento de iniciativas individuais. Disso decorre a interiorização, aplicação e reprodução das regras e dos princípios organizacionais por parte do indivíduo. O principal recurso utilizado é, na verdade, o que Foucault (1995) chama de "tecnologia do poder", um sistema de controle de poucos sobre muitos, por uma combinação de discursos e práticas, em geral, apoiada pela tecnologia da informação.

\section{Instância psicológica}

A aversão ao trabalho, característica da Grécia antiga, estava vinculada, diretamente, à rotina da utilização das mãos em contato com utensílios rudimentares, sem técnica nem criatividade. Era considerado degradante por sua simplificação, por dispensar qualquer qualificação e por suas atividades monótonas, além de jornadas de longa duração (CARMO, 1992).

Antes indigno, o trabalho passa a ser exaltado na sociedade moderna e contemporânea e a evidenciar a habilidade de "vencer na vida" pela atividade produtiva. Os bem-sucedidos sentem-se estimulados a trabalhar cada vez mais e, por este estímulo, forjam uma imagem de permanente satisfação com suas ocupações. A participação na abundância e o sucesso profissional são aspectos essenciais para a integração social; o desemprego gera sentimento de derrota (CARMO, 1992, p. 12-13).

Atualmente o trabalho é uma referência fundamental para o indivíduo, influenciando decisivamente, não apenas a construção de sua autoimagem e identidade individual, como também sua forma de inserção social.

Todavia, o processo de intensa racionalização resulta em maior alienação do trabalhador. Para Thiry-Cherques (2004), precisamos estar no mundo do trabalho para subsistir e continuar vivendo fisicamente, porém tal mundo 
está sempre separado dos mundos mental e emocional. Os trabalhadores adotam a estratégia de separação entre a vida e o trabalho, o viver e o trabalhar, cindindo sua autoimagem entre a parte que trabalha e a parte que vive -, a primeira é necessária unicamente para que a segunda subsista. Desse modo, o trabalho é sempre o trabalholabor, sacrifício; nunca o trabalho-opus, realização.

Desta perspectiva, Dejours (2006) esclarece como, hoje em dia, sob o argumento da racionalidade, a organização do trabalho choca-se diretamente com a vida mental e com a esfera das realizações, motivações e dos desejos do indivíduo, levando-o à perda do sentido na realização das tarefas.

Antunes (2003) afirma que, para que exista uma vida cheia de sentido fora do trabalho, é necessário que ela seja dotada de sentido dentro do trabalho. Trabalho assalariado, fetichizado e estranhado com o tempo não é compatível com os sentimentos de satisfação, realização e pertença que trazem sentido à vida dos indivíduos. Uma vida desprovida de sentido no trabalho não se coaduna com uma vida plena de sentido fora do trabalho.

\section{Percurso metodológico da pesquisa}

O presente estudo caracteriza-se pela adoção da abordagem qualitativa por proporcionar informações detalhadas e comprometer-se com o entendimento em profundidade de determinadas situações.

Entre as várias possibilidades que os métodos qualitativos apresentam, estão os estudos biográficos. Para Goldenberg (2000), a premissa da utilização do método biográfico é de que cada vida é dotada, ao mesmo tempo, de singularidade e universalidade; ou seja, "cada indivíduo é uma síntese individualizada e ativa de uma sociedade". Portanto, compreender a individualidade daquela vida é uma forma de inspirar-se para observar a realidade social.

Segundo Patton (1990, p. 155), o foco principal dos estudos biográficos pode ser sintetizado nesta frase: "O que esta narrativa ou história pode revelar sobre esta pessoa, ou sobre o "universo" no qual ela está inserida? De que maneira a narrativa pode ser interpretada para fornecer um entendimento sobre a vida e a cultura do sujeito investigado?".

Adotaram-se os procedimentos dos estudos biográficos com o objetivo de entender o sentido do trabalho para um indivíduo que atua em uma organização de cultura popular, com base em seu universo e na oralização da descrição do fenômeno estudado.

Weber (2003) distingue três tipos básicos de estudos biográficos: a biografia (ou autobiografia), a história de vida e a história oral, que podem ser classificados num continuum de amplitude, no qual a biografia encontra-se em um polo e a história oral em outro.

Neste trabalho, adotou-se a história oral como método de pesquisa que pode ser considerado um tipo de história de vida. Difere-se desta última em função da maior objetividade adotada tanto pelo pesquisador quanto pelo falante. O pesquisador apresenta um fato, ou uma questão específica, e colhe o depoimento de várias pessoas para buscar o entendimento do problema.

A história oral investigada refere-se à da líder Beth de Oxum, apresentada na próxima seção. A entrevista foi conduzida de modo não diretivo, como proposto por Pagès et al. (2006). Após um rápido diálogo com a protagonista deste estudo sobre os objetivos da pesquisa, a entrevista desenvolveu-se seguindo, na medida do possível, o ritmo de seu discurso. As intervenções das pesquisadoras, sobretudo no início da conversa, tiveram apenas o propósito de clarificar e aprofundar seu discurso.

Os dados oriundos desta narrativa foram examinados baseando-se na análise de conteúdo inspirada no método desenvolvido por Pagès et al. (2006). Enfrentando o problema metodológico de, por um lado, evitar o perigo positivista de só ler no discurso informações sobre a realidade externa e, por outro, o perigo idealista de só ver uma expressão do universo mental do indivíduo, estes autores (p. 22-23) fizeram a escolha metodológica de 
considerar que o discurso informa, simultaneamente, sobre realidades socioeconômicas e estruturas psicológicas que se influenciam mutuamente. Nesse caminho adotado, recusa-se a separação entre o "objetivo" e o "subjetivo", bem como o modo exclusivo por uma ou outra direção de análise (p. 206).

Concebida desta maneira, a análise do conteúdo visa compreender como os processos mentais, afetivos e cognitivos do sujeito da pesquisa são influenciados por estruturas sociais e as influenciam também. Em suma, busca-se analisar as estruturas sociomentais do universo do indivíduo (PAGÈS et al., 2006).

A unidade do discurso selecionada para tratamento é a unidade intencional do tema. Neste estudo, o tema dominante é o sentido do trabalho. Foram sublinhadas as passagens significativas do discurso e recortados fragmentos a serem interpretados (PAGÈS et al., 2006).

A vivência das pesquisadoras no campo das organizações da cultura popular e a observação constituíram-se, também, em técnicas qualitativas de coleta, complementadas por fontes secundárias de pesquisa, tais como documentos institucionais, extratos de entrevistas, reportagens, sites, além de teses e dissertações.

\section{Revelações da história de Beth}

\section{O Protagonismo de Beth de Oxum}

Beth de Oxum é filha de santo, uma ialorixá. Nasceu na antiga maternidade da Praça do Carmo, em Olinda-PE. Casou-se com Quinho, afrodescendente e neto de mestres do Coco. É mãe de quatro filhos, percursionista, cantora, compositora, coordenadora de um centro cultural.

\section{O protagonismo de Beth na Sambada de Coco}
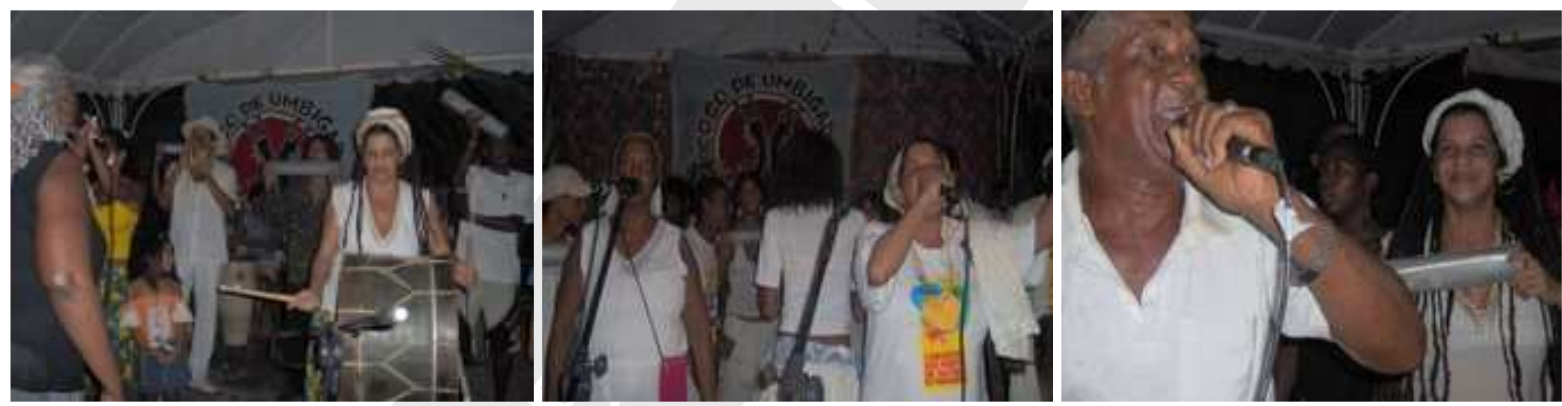

Sobre a aproximação com a música, ela conta que se deu em terreiros de candomblé. Por ser percursionista, o primeiro instrumento foi o agogô, aprendido nas festas do santo das quais participava. Diz que enfrentou preconceito dos membros dos afoxés pelo tom moreno claro de sua pele, e não negro como de costume, mas superou-os ao formar com outras mulheres um afoxé, um maracatu e um terreiro no quintal de sua casa, em Olinda, e na casa dos familiares, em Paratibe.

No histórico profissional, não possui formação superior; atuou como funcionária na iniciativa privada e como servidora pública. Seu primeiro emprego formal foi numa agência de turismo local; passou por outras agências, depois atuou como operadora de telemarketing de uma multinacional de máquinas de escrever e, finalmente, como servidora de um Hospital Universitário do Recife.

Em suas palavras, nunca foi feliz no que fazia. Precisou recorrer ao mercado de trabalho formal para garantir meios de ganhar dinheiro. Submeteu-se por necessidade; mas, quando teve seu terceiro filho, por inspiração religiosa, resolveu dedicar-se, exclusivamente, à Sambada de Coco, ao terreiro e à família, elementos centrais de sua vida e trabalho.

Chama atenção sua energia, seu jeito peculiar de falar e sua visão de mundo, normalmente avessa a tudo o que 
está hegemonicamente posto no mundo contemporâneo, ao que costumeiramente é ouvido e experimentado.

\section{A atividade laborativa e o locus do trabalho}

No levantamento histórico sobre o trabalho na vida de Beth, podem-se identificar alguns eventos determinantes. Em 1981, Beth, junto com um grupo de mulheres afrodescendentes insatisfeitas com a intolerância da sociedade pernambucana em relação ao candomblé - cujos rituais eram não só discriminados, mas proibidos, além de sofrer restrições internas dos afoxés (mais conhecido como candomblé de rua), que só permitiam a participação de negros e proibiam o gênero feminino de tocar os instrumentos da religião -, formaram um afoxé, em seguida um maracatu (o Maracatu Abadia) e um terreiro. Portanto, o grupo liderado por ela, introduziu mudanças ao enfrentar preconceitos sociais, machismo e incluir crianças de rua na tentativa de reeducá-las e inseri-las em um novo contexto social. Observa-se aí que, além da resistência às condições impostas, Beth contestou o que se estabelecera para outras pessoas como ela - morena, mulher e mãe - com o exercício do seu papel religioso e social.

Durante os últimos dez anos, seu grupo promoveu a música e a dança de raiz africana, mais precisamente o Coco da Aldeia - oriundo da pequena aldeia de Paratibe, no município de Paulista-PE, após a morte dos mestres, caiu no esquecimento por 40 anos. Esse longo período de afastamento da comunidade em relação às práticas culturais deveu-se à não aceitação e ao preconceito quanto às manifestações religiosas de origem africana: antigamente, para fazer a Sambada de Coco, era preciso ter autorização policial (LORENA, 2007).

O acesso e a aceitação de Beth na comunidade foram muito facilitados pelo fato de ela já ser companheira de Quinho, natural desta localidade. Uma das primeiras iniciativas do grupo foi tornar a Sambada de Coco de Umbigada um evento mensal, um meio de divulgação da dança e da música, possibilitando a troca de saberes dos mestres da cultura popular do Coco com a comunidade e seu entorno.

Outra realização de Beth foi a criação de um cine clube com projeções de filmes de conteúdo sobre a matriz africana, denominado "Cine Clube Macaíba", em alusão ao beco onde essa comunidade se encontra. Também esta foi uma forma de disseminar conteúdo alternativo ao que era veiculado pelas rádios da mídia tradicional.

\section{Imagens do Cine Clube em noite de exibição}
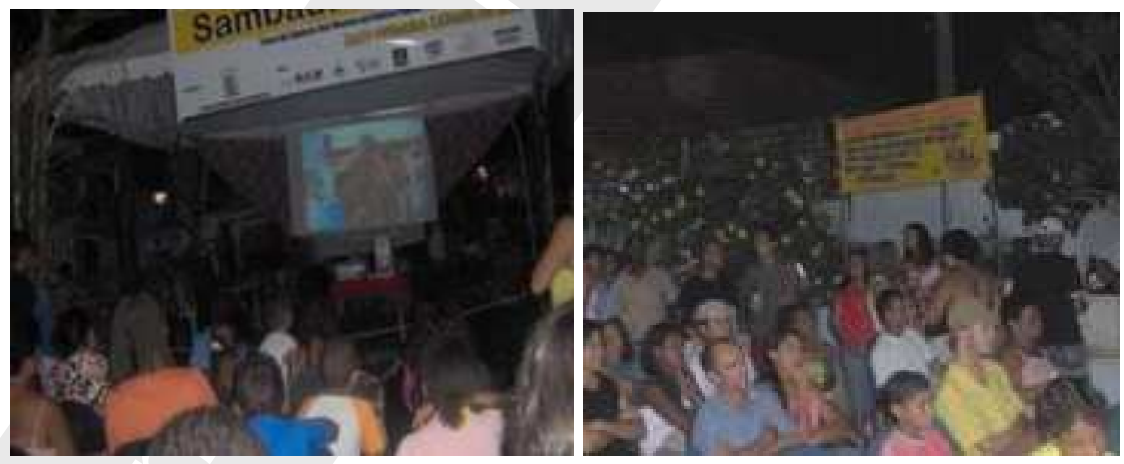

Tais iniciativas deixam transparecer suas ideias avessas à cultura massificada veiculada e introjetada na sociedade atual. Sua contestação evidencia-se em suas atitudes, em sua forma de agir e de viver. Em suas palavras, é preciso "empoderar-se" pela sua origem e pelo que é seu, não pela reprodução do que querem que sejamos.

Foi com o propósito de dar maior visibilidade às ações de "empoderamento" da matriz africana, que os integrantes do grupo, liderados por Beth, decidiram submeter dois projetos ao edital de lançamento do programa "Cultura Viva", do Ministério da Cultura, em 2004. Deste modo, foram criados dois pontos de cultura: o "Núcleo de Memória e Produção de Cultura Popular Coco de Umbigada" e o "Ensinamento de Mãe Preta" (troca de saberes tradicionais dos terreiros de candomblé de Pernambuco). O primeiro destina-se a ser 
referência na produção, pesquisa e acervo da cultura popular, em especial a cultura do Coco, e tem como público alvo a comunidade de baixa renda do bairro onde se localiza o centro. O segundo tem como escopo o "empoderamento" e a valorização da comunidade de candomblé de Olinda e Recife, principalmente no que tange ao gênero feminino, uma vez que o público alvo desse projeto são as mães de santo de candomblé. Sua ação final consiste na criação de uma rádio direcionada a essa crença (NOGUEIRA, 2007).

Estes dois projetos, juntos, compuseram o Centro Cultural Coco de Umbigada, instalado em uma casa vizinha ao terreiro que o originou - e que é a própria residência de Beth - localizado no largo de Guadalupe, bairro da cidade de Olinda, onde também mora a maioria de seus componentes e realizam-se suas ações. Lá as pessoas labutam, tocam, celebram cerimônias religiosas, educam os filhos uns dos outros e coabitam.

\section{Imagens de Guadalupe nos preparativos para a Sambada; Na noite da festa}
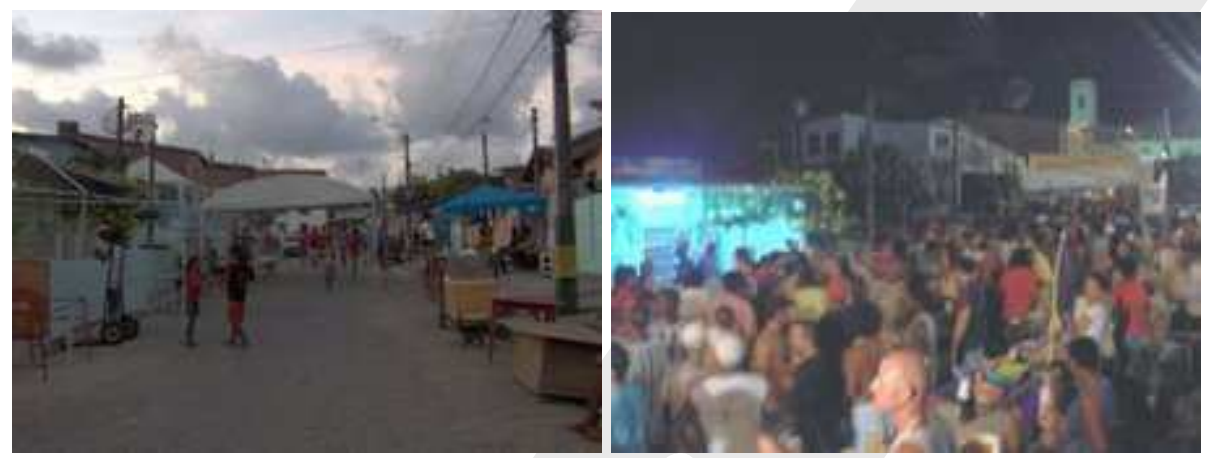

"Guadalupe tem um terreiro, é o terreiro da Umbigada, Dona Beth de Oxum vem trazendo essa cambada" (trecho da letra de uma das sambadas)

Em sua origem, o Centro Cultural foi formado por Mãe Lúcia (outra mãe de santo), Beth e seu companheiro Quinho. Hoje conta com mais três pessoas voluntárias que se identificaram com a organização e foram, nas palavras de Beth, "intuídas pelo santo", conciliando as atividades no grupo com outras ocupações. Entre suas ações, destacam-se a realização de oficinas de ritmo, teatro de bonecos, vídeo, os contos de Ifá (cidadania afrodescendente), além da continuidade da ação de preservação do patrimônio imaterial do povo negro e afrodescendentes com a Sambada de Coco.

Matéria do Diário de Pernambuco, veiculada em http://sambadadecoco.blogspot.com, que mostra o trabalho de Beth de Oxum na preservação do patrimônio imaterial do povo negro e afrodescendente

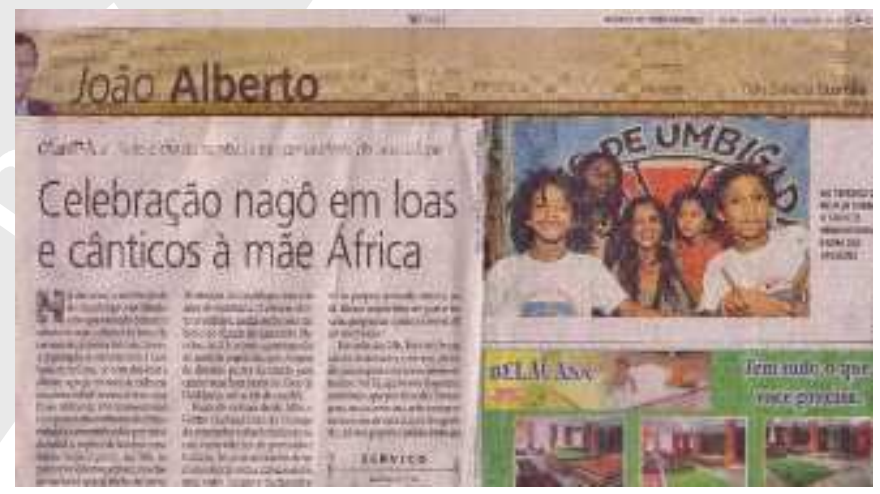

O locus de trabalho de Beth é a sua própria casa. Os recursos do projeto viabilizaram sua expansão na casa vizinha, alugada para esse fim. Beth entra e sai do Centro tal como faz em sua casa; lá cuida dos seus filhos, assim como dos filhos da comunidade. Isso pode ser visto em um dos momentos da coleta de dados, quando 
uma criança, ao passar a tarde entrando e saindo do Centro de Cultura, pergunta a Beth se era sua filha. Ao que ela responde: "é também", e explica que, embora não seja filha de sangue, é filha porque vive por ali sob seus cuidados. Ela incorpora o papel de mãe daquela comunidade. Assim, não há diferença entre a casa e o local de trabalho para Beth. Para o que faz para tocar um instrumento, cantar, receber gente da comunidade. Vai à rua "tomar uma cerveja" com a sua gente e também neste momento fala sobre suas idéias. Está trabalhando e a música ambiente vem da rádio comunitária, que só toca o que a comunidade quer e o que tem sentido e referência para a mesma.

Outro aspecto que merece destaque é a significância do elemento religioso para o trabalho na vida de Beth e no contexto desse tipo de organização. Várias questões são definidas, decisões tomadas, ações empreendidas com base nas orientações recebidas "do Santo" (baseado em inspirações espirituais).

Minha história é a música do terreiro. Eu não posso me afastar muito porque eu tenho as coisas assentadas. Eu tenho Exú assentado, tenho o caboclo assentado, tenho orixá assentado. Então eu não posso ficar muito tempo porque eu tenho que cuidar, limpar, ajeitar, fazer uma obrigação dependendo de cada época. Eu não posso ir pro mundo, seja lá com quem for. Eu tenho essa responsabilidade pessoal por assim dizer.

O desempenho de suas atividades de mãe de santo é condicionado à realização de sua maternidade, conforme demonstra o seguinte trecho de sua história oral:

[...] eu não posso querer ser, assim ter, esse negócio da ialorixá que é a mãe de santo sem ser mãe dos meus filhos. É uma contradição muito grande. Como você pode ser mãe de alguém, se você não pode ser mãe de seus filhos? Então essa contradição eu tive que resolver e foi trazendo a música pra dentro do terreiro.

\section{Coco de Umbigadinha; Jovens nas oficinas de inclusão digital}
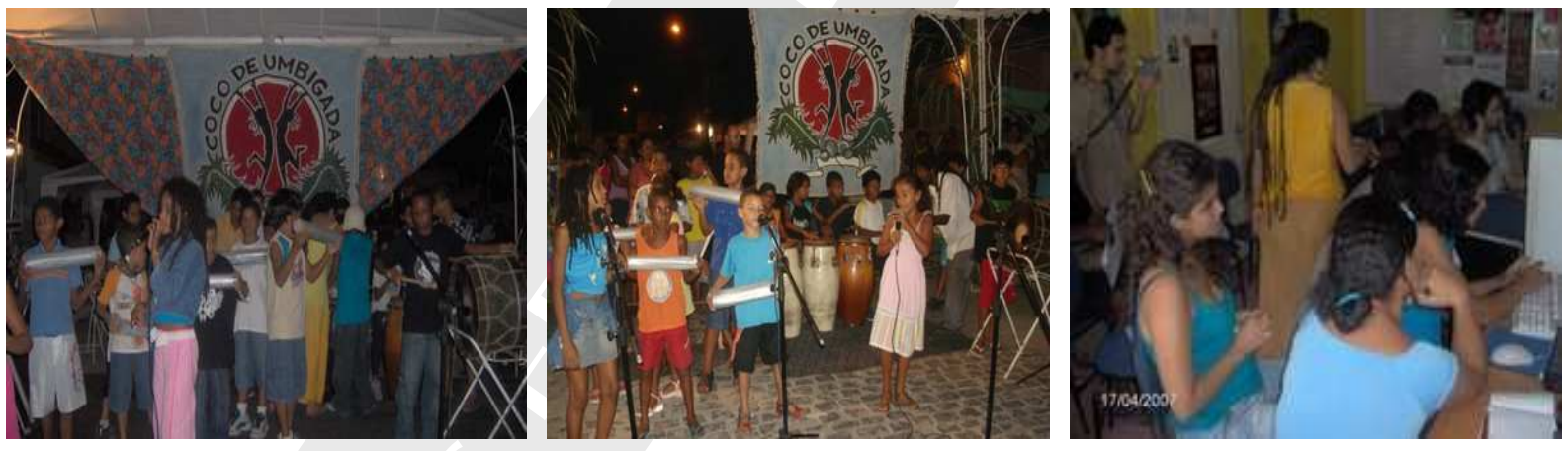

Ser coordenadora de um Ponto de Cultura, liderar a Sambada de Coco, ser mãe de santo, ser mãe de seus quatro filhos são atribuições da vida de Beth colocadas em um mesmo plano de valor. Portanto, não foi possível perceber uma distinção entre seu trabalho e sua vida, a música e sua religião, sua casa e o Centro Cultural.

Na realização dos trabalhos no Centro, as atividades são divididas de acordo com a identificação e a facilidade de desempenho de cada um, porém sempre em consonância com as atividades profissionais de cada integrante e voluntário. O Centro possui uma estrutura organizacional (se é que podemos chamar assim!) não disposta em organograma explícito, mas cada um sabe de suas obrigações e tarefas, distribuídas da seguinte maneira: um responsável pela sistematização da gestão e da tecnologia, outro pela articulação com o núcleo da música, uma voluntária que se encarrega da divulgação e visibilidade das ações, um voluntário que se responsabiliza pela organização e limpeza do espaço físico e um responsável pelas oficinas de ritmos e música, que é o esposo de Beth (NOGUEIRA, 2007, p. 82).

O trabalho de Beth consiste na coordenação de todas as atividades: organizar, divulgar, tocar percussão e cantar na sambada. Beth, portanto, faz de um tudo: toca, é líder religiosa, é coordenadora do projeto formal - e, assim, 
ela é Beth, sem nenhum cargo ou título antes de seu nome, acima de sua pessoa.

Sua liderança no grupo e seu protagonismo são muito evidentes na fala dos voluntários. Apesar desse reconhecimento de autoridade, as atividades no Centro se desenvolvem de forma participativa e democrática, como explícito no seguinte depoimento:

[...] ela é a gestora, ninguém passa na frente dela, ninguém pode, mas as decisões dela são aceitas, assim como ela aceita as nossas decisões, e isso é o bom do centro, porque ela sabe que eu não vou discutir com ela como esse axé tem que ser plantado e onde, do mesmo jeito que ela não vem discutir sobre colocação de cabos de som, entendeu? Tem essa troca, não é aquela coisa autoritária, é bem democrática e é bem aberta, ela abre pra todo mundo, não só dentro do núcleo, como dentro da banda (LORENA, 2007, p. 14).

A centralidade da figura de Beth, muito embora exerça a liderança na condução das atividades, ao mesmo tempo promove um contexto de trabalho onde todos são responsáveis por suas próprias atribuições. Seu papel no trabalho está intimamente relacionado com questões substantivas, como as religiosas e as da cultura afrodescendente. Mas, principalmente, seu papel parece ser fortalecido pela força de suas ideias no empoderamento da própria comunidade.

\section{O sentido do trabalho na vida de Beth}

Para Beth "o próprio sentido do trabalho, na nossa sociedade, ele é muito ruim, de fardo mesmo". Ela considera "indigna a condição dos nossos trabalhadores [...] nosso povo que trabalha literalmente pra comer e mal [...] é impressionante o fardo que o trabalho representa pro nosso trabalhador". Sua concepção sobre esse tipo de trabalho é de:

[...] uma coisa ruim [...] paga mal [...] não se faz com prazer [...] não tem futuro. E não é só o futuro financeiro não, é o futuro na perspectiva de cidadão mesmo. Como a maioria dos nossos irmãos, do nosso povo pobre, que tem que fiar [...] protegendo o patrimônio do bacana sem perspectiva nenhuma. Quer dizer, não dá, não dá.

Na narrativa de sua trajetória de trabalho, Beth comentou sobre suas experiências "dentro da iniciativa privada" para "[...] segurar a onda da grana", declarando ter feito "de tudo um pouco". Sua motivação provisória para o trabalho formal foi estritamente financeira.

Eu trabalhei como telemarketing [...] foi até legal. [...] Eu trabalhei em agência de turismo [...] foi o meu primeiro emprego [...] venda de passagem aérea, emissora de venda de bilhete aéreo [...] Depois eu trabalhei com a Olivetti do Brasil, coordenava as telemarketing, quer dizer eu cheguei pra ser uma delas, aí fui, depois eu me destaquei, aí ele me chamou pra ir coordenar e aí eu fui coordenar. Fiquei lá coordenando um tempão, aí depois eu passei num concurso na Universidade de Pernambuco. Aí fui parar no Osvaldo Cruz [...] fui parar na Faculdade de Medicina [...] no [setor] administrativo [...] depois no internato [...] um saco [...] mas aí também foi um aprendizado legal.

Sua recusa em continuar a trabalhar numa multinacional demonstra uma reação ao sistema de trabalho imposto neste tipo de organização. Para isso, decidiu mudar para o serviço público, numa tentativa de se sentir mais realizada no trabalho. Prestou, então, concurso público para um hospital estadual. Todavia, declarou não ter se identificado com as atividades desempenhadas no hospital público:

[...] eu sentia que era um fardo miserável. Que fardo era você trabalhar ali, naquele hospital enorme ou naquela faculdade, aí fica lá trabalhando, trabalhando, doido que chegue a hora de largar. Sem compromisso pedagógico nenhum, nenhum. 
Em paralelo, Beth estudava música, fazia oficinas e integrava o grupo de Lia de Itamaracá - merendeira numa escola pública estadual que, nas horas vagas, dedicava-se à musica e à ciranda, além de cantar e compor cocos de roda e maracatus. Ao tornar-se uma famosa cirandeira em Pernambuco, Lia alcançou popularidade no país e até no exterior, tendo feito inclusive uma turnê na Europa.

Beth decidiu pedir licença sem vencimentos do cargo que ocupava. Ao tomar esta decisão, negou o vínculo formal, a estabilidade do emprego e os vencimentos auferidos por meio dele para abraçar "a música literalmente"; passou a viajar fazendo shows:

Eu pedi licença sem vencimento porque teve uma hora [...] que o bicho pegou porque Lia viajou muito. [...] eu tive que tomar algumas decisões, ou eu ia ou eu ficava porque o pessoal não ajuda muito o servidor [público]. Complicado. Quando você tem um cargo que você têm cacife pra negociar, você negocia. Quando não, você tem que fazer a sua opção, sua escolha. Aí assim isso é um vácuo que está aberto, mas é uma coisa que eu não tenho o menor interesse, não tem futuro pra mim, entendeu? Eu fico indignada como entra ano, sai ano e aquelas pessoas ali. Não dá pra mim. Já deu. Agora o que eu aprendi ali foi legal e também segurou a onda de grana um bom tempo pra eu ficar me dedicando a estudar música [...] Eu tinha que segurar isso de manhã, e de tarde fazer outras coisas, já comecei fazer as oficinas [...] Depois eu fui incorporando mais a música.

Essas decisões de emprego podem ser consideradas como indícios de resistência ao emprego formal. Nos argumentos de Gorz (1982), Beth não pode ser considerada como membro da "não-classe-de-nãotrabalhadores" à medida que foi por opção pessoal e consciente que se opôs a participar do mercado de trabalho formal, tanto na iniciativa privada quanto no funcionalismo público do Estado. Ela não foi excluída do mercado de trabalho formal e, sim, excluiu-se consciente e propositadamente na busca de uma atividade laborativa que lhe conferisse mais realização pessoal. Na sua concepção,

[...] o que faz o fardo eu acho que é você ver que não tem perspectiva. Trabalhar por trabalhar. Tem gente que associa até o dinheiro, né? Trabalha que só a praga e ganha uma miséria. E outra coisa, a importância da gente. A gente tem que entender a importância da gente.

De algum modo, ela reconhece que essa experiência gerou um aprendizado relevante à realização de seu trabalho, mas disse que "não gostaria de carregar" em sua vida "o peso desse trabalho" sem identificação, sem perspectiva, sem compromisso ideológico.

Após o nascimento de sua terceira filha, decidiu diminuir o ritmo de trabalho: "desde que Maíra nasceu [...] eu disse: não vou mais pra rua [...] eu vou ficar em casa trabalhando, acreditando nessa proposta cultural". E já faz "dez anos de sambada, de ação, de inclusão [...] da extensão de tudo isso".

Referindo-se aos motivos que a levaram a renunciar às viagens para fazer shows, ela explica:

A essência de eu ter saído [...] a essência mesmo, foi o recado já do terreiro porque eu não podia ficar na música, no mundo.[...] o terreiro passou a ter outro papel na minha vida. Um papel de integração social, um papel de inclusão digital da comunidade, um papel concretamente pedagógico, um papel pedagógico dentro da comunidade [...] isso é trabalho, isso é a ampliação da música. A partir do momento que eu disse eu não quero ficar mais só nos palcos: aí tome trabalho. Mas é um trabalho também muito bom, mas também de muita responsabilidade. O papel de trabalho [...] se aplica a cada dia [...] Isso é trabalho, isso é barganha, isso é uma ampliação.

Esse relato também mostra que os elementos subjetivos compõem a compreensão de trabalho para Beth. Em sua vida, no terreiro, na comunidade e na música, barganha e responsabilidade são elementos que formam o mosaico de sua atividade laborativa.

Beth assumiu a centralidade de seu papel para a sua comunidade. Apesar de ressentir-se de uma formação que propiciasse maior destreza para cumprir as exigências dos editais na área da cultura, ela tentou superar seu 
relativo despreparo por meio da resistência, como demonstra o seguinte trecho de seu depoimento:

[...] eu, na indignação, antes da minha amiga chegar, eu compus o projeto todinho, sabe? Eu peguei uma página em branco e era isso mesmo, era esse sentimento, quem tinha que retratar era eu mesma. Aí fiz, mandei, passou, que é esse Ponto de Cultura. A partir daí, depois, eu saquei o potencial que podia. Teve a ação Griô, cheio de Mestre Coquista aqui. O povo de mestrado dentro de casa que era aqui, [...] Porque quando o edital pintou era pra você estender essa relação pedagógica dos mestres com a universidade e com a escola. Desse espaço, desse universo do trabalho, que a gente tá tendo aqui. O espaço de trabalho da gente ampliou muito.

A trajetória de vida de Beth demonstra seu comprometimento com a africanidade, a questão de gênero, a cidadania (LORENA, 2007, p. 18). Ela define seu trabalho como "uma coisa que tem outra ótica":

[...] envolve a família, já envolve as crianças. Por exemplo, eu paro e digo vamos fazer um ensaio com Coco de Umbigadinha. Mais tarde tô na oficina [...] Esse trabalho é um trabalho que se mistura com minha vida, se mistura com a minha família, se mistura [...] Por exemplo, sábado eu tava aqui, aí eu tava até ajeitando o plano de trabalho de Mãe Preta [...] aí eu fechei o computador, contratei uma pessoa pra me ajudar, que ela mexe no Excel e eu não mexo. Aí a galera tava tomando uma aí na frente com os vizinhos e tudo aí gritando: bora, Beth! [...] Eu fiquei o resto do dia. Já tinha tomado uma, diga-se de passagem. Aí tomei ali com a galera, e os meninos ali brincou e a gente começou a tocar afoxé, brincamos ali mesmo. Mistura um pouco, sabe essa coisa, mistura um pouco. Mas eu acho que é legal, assim, é bom.

Ela reconhece que seu trabalho "é diferente, é um trabalho que agrega, é trabalho que "empodera" uma comunidade [...] [que] vai crescendo [...] envolvendo mais pessoas". E ela conclui sua fala do seguinte modo: "Moral da história: ou o trabalho tem esse fio condutor da cidadania, da espiritualidade ou ele vai te matar muito cedo, vai te revoltar, [...] tu não vai segurar".

O cruzamento das várias perspectivas do sentido do trabalho discutidas na fundamentação e as evidências levantadas nessa pesquisa fornecem indícios de resistência na relação de Beth com seu trabalho, na medida em que ela se opõe aos meios formais de subsistência recorrendo ao trabalho realizado entre o Centro Cultural, o Terreiro de Candomblé, a casa e a comunidade. Se, de um lado, de acordo com a corrente ideológica dominante, o trabalho ganhou conotação de divindade; de outro, para Beth, foi justamente sua relação com a divindade que a afastou do emprego formal.

Se analisado sob a ótica da instância econômica, a centralidade do trabalho na vida do homem é condição para geração de riqueza e, consequentemente, de boas condições de vida. No caso de Beth, foi o distanciamento desse tipo de trabalho que promoveu condições de ter dignidade de vida e de se dedicar a aspectos substantivos da vida humana como a religião, a família e sua comunidade.

Na perspectiva política, o trabalho realizado no âmbito das organizações econômicas desenvolve-se por meio de práticas voltadas para a mediação de interesses contraditórios entre os indivíduos e a organização. Para Beth, a organização que ela criou configura a possibilidade de realização de seus próprios ideários de vida. Portanto, não existe a mediação, porque simplesmente inexiste o conflito de interesses.

Por fim, analisado sob a ótica da perspectiva psicológica, o trabalho moderno, movido pelo argumento da racionalidade, está focado nos resultados de produtividade, eficácia e eficiência. Para Beth é o trabalho no âmbito de sua casa, por meio da religião e da música, que lhe confere a verdadeira realização. Seus indicadores baseiam-se no bem-estar de sua família e de sua comunidade. 
Quadro 1 - Contraponto Pressupostos Teóricos $x$ Sentido do trabalho na vida de Beth

\begin{tabular}{|c|c|c|}
\hline Instâncias & Principais Pressupostos & $\begin{array}{l}\text { Sobre o sentido do trabalho na vida de } \\
\text { Beth }\end{array}$ \\
\hline Instância ideológica & $\begin{array}{l}\text { Trabalho passou de fardo à vocação, } \\
\text { tornando-se um fim absoluto em si } \\
\text { mesmo, ganhando conotação de } \\
\text { divindade, cuja veneração foi } \\
\text { transferida para os progressos } \\
\text { técnicos na modernidade. }\end{array}$ & $\begin{array}{l}\text { A inspiração do "santo" foi o fato que a } \\
\text { motivou a abandonar o emprego formal, } \\
\text { levando-a para casa, para dedicar-se a criar } \\
\text { seus filhos e para intensificar seu } \\
\text { protagonismo no terreiro de candomblé. }\end{array}$ \\
\hline Instância econômica & $\begin{array}{l}\text { O trabalho ocupa uma posição } \\
\text { central na vida das pessoas como } \\
\text { provedor de boa condição de vida. O } \\
\text { não trabalho no sentido de } \\
\text { desemprego e exclusão do } \\
\text { trabalhador do processo social de } \\
\text { produção de serviços e riquezas } \\
\text { assume conotação negativa. }\end{array}$ & $\begin{array}{l}\text { Decisão de abandono do emprego formal e } \\
\text { distanciamento dos meios formais de } \\
\text { produção de serviços e de riquezas } \\
\text { proporcionaram condições de ter dignidade } \\
\text { de vida e de se dedicar a aspectos } \\
\text { substantivos da vida humana, como a } \\
\text { religião, a família e sua comunidade. }\end{array}$ \\
\hline Instância política & $\begin{array}{l}\text { As organizações têm desempenhado } \\
\text { o papel fundamental de mediar as } \\
\text { contradições do sistema econômico } \\
\text { vigente, nomeadamente o conflito de } \\
\text { interesses do capital e interesses dos } \\
\text { trabalhadores }\end{array}$ & $\begin{array}{l}\text { Na vida de Beth, seus interesses e ideais de } \\
\text { vida são coincidentes com os do Centro } \\
\text { Cultural Coco de Umbigada, que surgiu } \\
\text { como forma de realizar esses anseios. }\end{array}$ \\
\hline Instância psicológica & $\begin{array}{l}\text { Sob o argumento da racionalidade, o } \\
\text { trabalho está organizado para } \\
\text { produtividade, eficácia e eficiência } \\
\text { de forma a confrontar-se com a vida } \\
\text { mental e com a esfera das } \\
\text { realizações, motivações e desejos do } \\
\text { indivíduo, levando-o à perda do } \\
\text { sentido na realização das tarefas. }\end{array}$ & $\begin{array}{l}\text { Decide pelo trabalho associado à sua } \\
\text { religiosidade, à cultura popular, ao prazer } \\
\text { da música, à sua integração com sua casa e } \\
\text { com sua família. }\end{array}$ \\
\hline
\end{tabular}

Fonte: Construção das autoras

Assim, pode-se afirmar que, para a protagonista desta história oral aqui apresentada, o trabalho tem outra possibilidade, que não a empresarial e, naturalmente, outro sentido, envolvendo elementos substantivos que geram sua motivação e sua realização nas dimensões individual, social e organizacional.

\section{Considerações finais}

À frente do Centro Cultural Coco de Umbigada, o trabalho para Beth mostrou-se pleno de sentidos: trata-se de uma atividade autodeterminada, externa à relação dinheiro-mercadoria, que gera realização pessoal e coletiva, desenvolvimento da comunidade, exercício de uma nova cidadania e, principalmente, da palavra que talvez seja a mais pronunciada por ela: "empoderamento".

A luta contra a discriminação racial e de gênero, a espiritualidade, o amor pela cultura africana e o compromisso social levaram Beth a recusar carregar o fardo, ruim e pesado, do trabalho na iniciativa privada e no funcionalismo público, realizado para fins de sustento, mas, sem perspectiva futura em todas as dimensões humanas. Em seu discurso é notório o clamor por representatividade, reconhecimento social em relação à raça e 
gênero, e valorização cultural.

Os relatos de Beth emergiram da prática de resistência, por isso, ela promove este conceito com sua vida e com as atividades que desenvolve; opõe-se ao trabalho formal e às condições de vida impostas pela lógica de mercado e, por meio das atividades desenvolvidas no Centro Cultural, contesta os hábitos e a cultura veiculada pela mídia dominante. Sem dúvida, a cultura popular realiza práticas dotadas de uma lógica que as transforma em atos de resistência (CHAUÍ, 1989).

Assim, este estudo incita o desenvolvimento e a ampliação de novos estudos sobre o sentido do trabalho em organizações não empresariais, se incluídos os construtos teóricos de resistência, contestação e participação. Desta maneira, é possível contribuir com outra possibilidade de trabalho que não a dominante, questionando o status quo e seus efeitos sobre o homem.

Ao levantar outras possibilidades de sentido de trabalho, o presente estudo cumpre seu papel constestador do mainstream sobre relações de trabalho, corroborando o argumento de Faria (2004, p. 1) de que:

[...] a teoria das organizações necessita também de compreensões outras, além das usualmente conhecidas, porque estudos divulgados atualmente, na sua maioria, tendem à uniformidade, à visão funcional e a destituir os princípios questionadores das contradições inerentes às organizações

Mediante o levantamento de aspectos sobre um trabalho diferente do hegemonicamente imposto, espera-se gerar discussões sobre outras possibilidades de vida e de trabalho, corroborando o pensamento de Antunes (2003, p. 183) de que a humanidade pode conferir ao ato laborativo um sentido completamente diverso ao dado pelo capital. 


\section{Referências}

ANTUNES, Ricardo. Os sentidos do trabalho: ensaio sobre a afirmação e a negação do trabalho. 6. reimp. São Paulo: Boitempo editorial, 2003.

ARENDT, Hanah. A condição humana. 9. ed. Rio de Janeiro: Forense Universitária, 1999.

CARMO, Paulo Sérgio do. A ideologia do trabalho. São Paulo: Moderna, 1992.

CHAUÍ, Marilena. Conformismo e resistência: aspectos da cultura popular. 4. ed. São Paulo: Brasiliense, 1989.

CUNHA, Newton. A felicidade imaginada: a negação do trabalho e do lazer. São Paulo: Brasiliense, 1987.

DEJOURS, Christophe. A loucura do trabalho: estudo de psicopatologia do trabalho. São Paulo: Cortez-Oboré, 1987.

. A banalização da injustiça social. Rio de Janeiro: FGV, 2006.

DOURADO, Débora Coutinho Paschoal. Qualidade de vida no trabalho: propósitos organizacionais e mecanismos de alienação do homem. 2007. 227f. Tese (Doutorado em Administração) - Programa de Pós-Graduação em Administração da Universidade Federal de Pernambuco, Recife.

FARIA, José Henrique. Economia política do poder. Curitiba: Juruá Editora, 2004. 2 v.

FOUCAULT. M. Discipline and punish. Random House: 1995.

GOLDENBERG, M. A arte de pesquisar: como fazer pesquisa qualitativa em Ciências Sociais. Rio de Janeiro: Record, 2000.

GORZ, André. Adeus ao proletariado: para além do socialismo. Rio de Janeiro: Forense Universitária, 1982.

. Metamorfoses do trabalho: crítica da razão econômica. São Paulo: Annablume, 2003

LORENA, Ana Luiza Freire de. As mulheres na preservação da identidade cultural: o caso Núcleo de Memória e Produção de Cultura Popular Coco de Umbigada. 2007. Relatório Final (Atividades de Iniciação Científica) - Programa Institucional de Bolsa de Iniciação Científica - Universidade Federal de Pernambuco - Conselho Nacional de Desenvolvimento Científico e Tecnológico, Recife.

MORIN, Estelle. Os Sentidos do Trabalho. RAE - Revista de Administração de Empresas, São Paulo: v. 41, n. 3, p. 819, jul./set., 2001.

MORIN, Estelle M.; TONELLI, Maria José; PLIOPAS, Ana Luisa Vieira. O Trabalho e Seus Sentidos. In: ENCONTRO NACIONAL DA ASSOCIAÇÃO DOS PROGRAMAS DE PÓS-GRADUAÇÃO EM ADMINISTRAÇÃO, 27., 2003, Atibaia. Anais... Atibaia: Anpad, 2003.

NOGUEIRA, Alessandra Cabral. Pontos de cultura, particularidades na gestão? um estudo na primeira capital brasileira da cultura. 2007. 149f. Dissertação (Mestrado em Administração) - Programa de Pós-Graduação em Administração da Universidade Federal de Pernambuco, Recife.

OLIVEIRA, Sidinei Rocha de. Os Sentidos do trabalho para os dentistas filiados à Uniodonto. 2004.143 p. Dissertação (Mestrado em Administração) - Programa de Pós-Graduação em Administração da Universidade Federal do Rio Grande do Sul, Porto Alegre.

OLIVEIRA, Carlos Roberto. História do Trabalho. Série Princípios. São Paulo: Ática, 1991.

ORGANISTA, José Henrique Carvalho. O Debate sobre a centralidade do trabalho. São Paulo: Editora Expressão Popular, 2006.

PAGÈS, Max et al. 0 poder das organizações. São Paulo: Atlas, 2006.

PATTON, Michael Quinn. Qualitative evaluation methods. 3. ed. London: Sage Publications, 1990.

THIRY-CHERQUES, Hermano Roberto. Sobreviver ao trabalho. Rio de Janeiro: FGV, 2004.

THOMPSON, Edward P. A formação da classe operária inglesa. v. 2. Rio de Janeiro: Paz e Terra, 1987.

WEBER, Max. A ética protestante e o espírito do capitalismo. São Paulo: Matin Claret, 2002.

WEBER, Silke. Anotações de sala da aula da palestra intitulada Estudos Biográficos, ocorrida em 25 de março de 2003. Auditório do Centro de Ciências Sociais Aplicadas, Universidade Federal de Pernambuco. 